\title{
Evidence for the agricultural origin of antimicrobial resistance in a fungal pathogen of humans
}

\author{
Authors and affiliations \\ S. Earl Kang ${ }^{1,3}$, Leilani G. Sumabat ${ }^{2,4}$, Tina Melie ${ }^{2,5}$, Brandon Mangum ${ }^{1,2}$, Michelle Momany ${ }^{1 *}$, Marin T. Brewer ${ }^{2 *}$ \\ ${ }^{1}$ Fungal Biology Group \& Plant Biology Department, University of Georgia, Athens, GA \\ ${ }^{2}$ Fungal Biology Group \& Plant Pathology Department, University of Georgia, Athens, GA \\ ${ }^{3}$ Current address: Fungal Team, Ginkgo Bioworks, Boston, MA \\ ${ }^{4}$ Current address: Institute of Biology, University of the Philippines Diliman, Quezon City, Philippines \\ ${ }^{5}$ Current address: Ecology and Evolutionary Biology Department, University of Colorado, Boulder, CO \\ * Corresponding authors
}

\begin{abstract}
Resistance to clinical antimicrobials is an urgent problem, reducing our ability to combat deadly pathogens of humans. Azole antimicrobials target ergosterol synthesis and are highly effective against fungal pathogens of both humans and plants leading to their widespread use in clinical and agricultural settings ${ }^{1,2}$. The fungus Aspergillus fumigatus causes 300,000 life-threatening infections in susceptible human hosts annually and azoles are the most effective treatment ${ }^{3}$. Resistance to clinical azole antifungals has become a major problem in Europe and India over the last decade, where identical mutations in cyp51A, an ergosterol biosynthetic gene, have been found in strains from both clinical and agricultural settings ${ }^{4}$. Shared cyp51A genotypes suggest that clinical azole resistance might have had an agricultural origin; however, until now, independent origins of clinical and agricultural mutations could not be ruled out. Here we show that azole-resistant isolates of $A$. fumigatus from clinical and agricultural settings also carry mutations conferring resistance to quinone outside inhibitor (QoI) fungicides, which are used exclusively in agricultural settings. This is the first report of a clear marker for the agricultural origin of resistance to a clinical antifungal. We anticipate that our work will increase the understanding of interactions between pathogens of plants and pathogens of humans.
\end{abstract}

\section{Main}

Fungi are important pathogens of humans, causing over 1.5 million deaths annually 5 . Fungi are also important pathogens of plants, causing crop losses of $20 \%$ and postharvest losses of $10 \%$. The filamentous fungus Aspergillus fumigatus is a saprobe found in a variety of environments including soil, compost, and decaying plant material; however, in immunocompromised individuals it can cause the devastating disease aspergillosis. Azoles are often used as the first line of defense against aspergillosis. During the last decade Europe and Asia have seen an alarming increase in azole-resistant $A$. fumigatus in the clinic and azole resistance is now present on 6 continents ${ }^{7}$. Though some resistance has been associated with long-term azole therapy in patients with chronic infections, at least twothirds of patients with azole-resistant $A$. fumigatus infections have not previously undergone azole therapy ${ }^{8,9}$. The environmental use of azoles has been proposed to be the driving force for the majority of clinical resistance in $A$. fumigatus with several studies suggesting that most azole-resistant isolates originated from widespread agricultural use of azoles to combat plant-pathogenic fungi ${ }^{10,11}$.

The same mutations in cyp51A - which encodes the ergosterol biosynthetic protein targeted by azoles - have been reported in strains from both clinical and agricultural settings in Europe, Asia, Africa, and the Middle East ${ }^{4,7,9,12}$. Several point mutations and tandem repeats (TR) within the promoter, including $\mathrm{TR}_{34} / \mathrm{L} 98 \mathrm{H}$ and $\mathrm{TR}_{46} / \mathrm{Y} 121 \mathrm{~F} / \mathrm{T} 289 \mathrm{~A}$, are commonly associated with azole resistance in environmental isolates. Isolates with the $\mathrm{TR}_{34} / \mathrm{L} 98 \mathrm{H}$ and $\mathrm{TR}_{46} / \mathrm{Y} 121 \mathrm{~F} / \mathrm{T} 289 \mathrm{~A}$ alleles show high levels of resistance to multiple azole drugs (pan-azole resistance) and patients infected with these isolates have higher rates of treatment failure and death ${ }^{13}$. Though the presence of $\mathrm{TR}_{34} / \mathrm{L} 98 \mathrm{H}$ and $\mathrm{TR}_{46} / \mathrm{Y} 121 \mathrm{~F} / \mathrm{T} 289 \mathrm{~A}$ alleles in both agricultural and clinical isolates suggested that azoleresistant clinical strains of $A$. fumigatus might have had an agricultural origin, independent evolution of these mutations in both settings has not been previously excluded. 
In the Unites States (U.S.), azole-resistant A. fumigatus strains with $\mathrm{TR}_{34} / \mathrm{L} 98 \mathrm{H}$ and $\mathrm{TR}_{46} / \mathrm{Y} 121 \mathrm{~F} / \mathrm{T} 289 \mathrm{~A}$ alleles have been recently reported in patients ${ }^{14,15}$. Additionally, azole-resistant $A$. fumigatus isolates with $\mathrm{TR}_{34} / \mathrm{L} 98 \mathrm{H}$ alleles were detected in a peanut field in Georgia ${ }^{16}$. Otherwise, very little information about the frequency of azole-resistant $A$.

fumigatus in agricultural settings in the U.S. is available. To investigate the prevalence of azole-resistant A. fumigatus in agricultural environments in the U.S., we collected soil and plant debris from 56 sites across Georgia and Florida, including 53 sites with a history of azole fungicide use, two organic sites with no fungicide use for at least 10 years, and one compost pile of unknown history (Supplementary Table S1). We recovered 700 isolates of A. fumigatus from soil, plant debris, and compost. Isolates were screened for sensitivity to the azole fungicide tebuconazole (TEB) that has widespread use in agriculture. Of the 700 isolates collected, 123 (17.6\%) grew on solid medium amended with 3 $\mu \mathrm{g} / \mathrm{ml}$ TEB. None of the isolates collected from the two organic sites grew on TEB-amended plates.

Minimal Inhibitory Concentrations (MIC) for TEB, itraconazole (ITC), voriconazole (VOR), and posaconazole (POS) were determined by broth dilution assays for the 123 isolates that grew on TEB-amended solid medium, and for 49 isolates from the same sites that that did not grow on the amended medium. MIC ranged from 0.5 to $>16$ $\mu \mathrm{g} / \mathrm{ml}$ for TEB, 0.5 to $2 \mu \mathrm{g} / \mathrm{ml}$ for ITC, 0.125 to $>16 \mu \mathrm{g} / \mathrm{ml}$ for VOR, and 0.06 to $1 \mu \mathrm{g} / \mathrm{ml}$ for POS. Recommended clinical breakpoints of antifungal resistance for A. fumigatus ${ }^{17}$ are $>2 \mu \mathrm{g} / \mathrm{ml}$ for ITC and VOR and $>0.25 \mu \mathrm{g} / \mathrm{ml}$ for POS; however, EUCAST notes there is uncertainty regarding the cutoff values for POS and some data suggest the cutoff value of $>1 \mu \mathrm{g} / \mathrm{ml}$, which we use here, may be more relevant. Although many of the isolates showed low levels of azole resistance, only 12 of the 123 isolates were highly resistant at clinically relevant levels (Supplementary Tables S1 and S2). The 12 isolates exhibited high levels of resistance to both TEB and VOR with MIC $\geq 16 \mu \mathrm{g} / \mathrm{ml}$, and decreased sensitivity to ITC and POS (Table 1), showing they are pan-azole resistant.

To determine whether mutations in cyp51A were associated with azole resistance, we sequenced 1,286 bp of cyp51A, including the promoter and downstream regions, for 123 isolates that grew on TEB-amended medium and for 49 TEB-sensitive isolates from the same sites. The 12 pan-azole-resistant isolates had the $\mathrm{TR}_{46} / \mathrm{Y} 121 \mathrm{~F} / \mathrm{T} 289 \mathrm{~A}$ allele (Table 1) that underlies high levels of resistance to $\mathrm{VOR}^{10,12}$. We did not detect the $\mathrm{TR}_{34} / \mathrm{L} 98 \mathrm{H}$ allele that is the most prevalent worldwide in azole-resistant environmental and clinical isolates of A. fumigatus. Failure to detect the $\mathrm{TR}_{34} / \mathrm{L} 98 \mathrm{H}$ allele does not necessarily mean this set of mutations is absent in the areas we sampled, but more likely reflects our initial screen for resistance with TEB. TEB is an azole with a similar structure to VOR, and resistance to TEB has previously been associated with the $\mathrm{TR}_{46} / \mathrm{Y} 121 \mathrm{~F} / \mathrm{T} 289 \mathrm{~A}$ mutations ${ }^{18}$. Eleven of the isolates sequenced had the I242V mutation in Cyp51A and 5 had the Y46F/V172M/T248N/E255D/K427E mutations found in the reference isolate Af293. These 16 isolates with non-synonymous mutations in cyp51A, but without tandem repeats in the promoter, had slightly elevated MIC values for TEB, VOR, and POS compared to the sensitive reference isolate A1 163 (Table 1). Increased MIC values for isolates with these mutations have been described previously ${ }^{19-21}$; however, it is not clear if these specific mutations are the cause of increased drug resistance.

To determine the relationship of agricultural isolates from Georgia and Florida to clinical isolates from the same region, we used 9 STRA $f$ markers ${ }^{22}$ to genotype the 168 agricultural isolates that we collected along with 48 clinical isolates collected between 2015 and 2017 by the Centers for Disease Control and Prevention ${ }^{23}$. None of the clinical isolates were azole resistant. Based on microsatellite data almost every isolate had a unique genotype (Supplementary Figure S1). The combined environmental and clinical A. fumigatus population from Georgia and Florida showed no genetic structure, except for the pan-azole-resistant agricultural isolates that had the $\mathrm{TR}_{46} / \mathrm{Y} 121 \mathrm{~F} / \mathrm{T} 289 \mathrm{~A}$ allele. These pan-azole-resistant isolates comprised a single lineage and were isolated from a compost pile and pecan debris from a processing facility (Supplementary Table S1). Our results are consistent with previous studies showing that $A$. fumigatus is panmictic with little population structure either by geographic region or clinical versus agricultural setting ${ }^{9,24}$.

To better understand the relationship of Georgia and Florida agricultural isolates to worldwide environmental and clinical isolates, we performed whole genome sequencing on 89 strains representing all of our field sites and combined them with 69 publicly available whole genome sequences to construct a neighbor-joining tree (Figure 1; Supplementary Table S3). Clinical and environmental azole-resistant isolates (open or closed red circles) from the United States (USA), United Kingdom (UK), Spain (ESP), the Netherlands (NL), and India (IND) were distributed throughout the tree; however, the four pan-azole-resistant isolates from this study that carried cyp51A TR mutations 
109

110

111

112

113

114

115

116

117

118

119

120

121

122

123

124

125

126

127

128

129

130

131

132

133

134

135

136

137

138

139

140

141

142

143

144

145

146

147

148

149

(closed red circles) clustered into a well-supported clade with clinical and environmental isolates carrying cyp51A TR mutations from the UK, IND and NL (red branches). This clade also included azole-sensitive isolates from diverse geographic origins. Although A. fumigatus does not show population structure by geographic or environmental origin, our data support population structure by pan-azole resistance. The genetic relatedness of pan-azole-resistant isolates across geographic locations and environment types has been previously described ${ }^{9,24}$ and suggests that there is a barrier to gene flow or some other genetic predisposition in this pan-azole-resistant clade allowing cyp51A TR mutations to arise and/or persist.

To delay the evolution and spread of antifungal resistance in agricultural settings, azoles are generally applied to crops in alternation or combination with other fungicides such as the quinone outside inhibitors (QoI) and, to a lesser extent, benzimidazoles (MBC) ${ }^{25,26}$. QoI fungicides target the protein encoded by the cytochrome $B$ (cytB) gene and are used on crops, but not on patients ${ }^{27}$. MBC fungicides target the protein encoded by the $\beta$-tubulin (benA) gene and were widely used in U.S. agriculture in the 1970s. MBCs are used much less in U.S. agriculture now due to resistance development, but they are used clinically as antihelminthics ${ }^{28}$. We reasoned that if isolates of A. fumigatus had acquired azole-resistance in agricultural settings, they might also have acquired resistance to these non-azole fungicides. To determine if azole-resistant isolates carried mutations conferring resistance to QoI and MBC fungicides, we searched the genomes of our agricultural isolates along with the genomes of publicly available $A$. fumigatus isolates (Supplementary Table S3). We detected the cytB G143A mutation known to cause QoI resistance (Figure 1, orange circles; Table 2) and/or the benA F219Y mutation known to cause MBC resistance (Figure 1, violet circles; Table 2) in 14 clinical and environmental isolates, including four from Georgia agricultural sites. To verify that these mutations were associated with fungicide resistance, we tested growth on media amended with QoI or MBC fungicides for the four Georgia isolates carrying $c y t B$ and benA mutations (eAF222, eAF233, eAF234, eAF513) and four Georgia isolates not carrying these mutations (eAF77, eAF94, eAF128, eAF537). Only isolates with the $c y t B$ G143A mutation grew on medium with the QoI fungicide azoxystrobin and only isolates with the benA F219Y mutation grew on medium with the MBC fungicide benomyl (Supplementary Figure S2, Supplementary Table S4).

Fourteen of 19 pan-azole-resistant isolates included in our study also carried mutations for QoI resistance, MBC resistance, or both. All QoI-resistant and MBC-resistant mutants were also pan-azole resistant and clustered in the well-supported pan-azole clade (Figure 1, red branches). Eight of these multi-fungicide-resistant isolates were from agricultural sources in the United States and India and 6 were from clinical sources in the Netherlands and India. Four of these clinical isolates carried mutations conferring resistance to both MBC and QoI fungicides. That panazole-resistant $A$. fumigatus strains from patients carry the mutation for resistance to QoI fungicides used exclusively for plant protection shows definitively that these strains have an agricultural origin. However, not all pan-azole resistant isolates in our study showed this definitive signature of agricultural origin. Five of 19 pan-azole-resistant clinical isolates did not carry $\mathrm{MBC}$ or QoI fungicide-resistance mutations raising the possibility that they could have originated from nonagricultural sources. We found pan-azole-resistant A. fumigatus in a single clade on three continents. We also found resistance to $\mathrm{MBC}$ and QoI fungicides exclusively in this clade and always in combination with pan-azole resistance. Beyond showing the agricultural origin of clinical pan-azole resistance, our results suggest that the unique genetics of the pan-azole clade enable the evolution and/or persistence of antimicrobial resistance mutations. 


\section{References}

$151 \quad 1 \quad$ Klittich, C. J. Milestones in Fungicide Discovery: Chemistry that Changed Agriculture. Plant Health Progress 9, 31 (2008).

Sheehan, D. J., Hitchcock, C. A. \& Sibley, C. M. Current and emerging azole antifungal agents. Clin Microbiol Rev 12, 40-79 (1999). Aspergillosis: 2016 Update by the Infectious Diseases Society of America. Clin Infect Dis 63, 433-442, doi:10.1093/cid/ciw444 (2016). Can We Retain the Clinical Use of Mold-Active Antifungal Azoles? Clin Infect Dis 62, 362-368, doi:10.1093/cid/civ885 (2016).

5 Brown, G. D. et al. Hidden killers: human fungal infections. Sci Transl Med 4, 165rv113, doi:10.1126/scitranslmed.3004404 (2012).

6 Fisher, M. C., Hawkins, N. J., Sanglard, D. \& Gurr, S. J. Worldwide emergence of resistance to antifungal drugs challenges human health and food security. Science 360, 739-742, doi:10.1126/science.aap7999 (2018).

7 Resendiz Sharpe, A. et al. Triazole resistance surveillance in Aspergillus fumigatus. Med Mycol 56, 83-92, doi:10.1093/mmy/myx144 (2018).

8 Bowyer, P. \& Denning, D. W. Environmental fungicides and triazole resistance in Aspergillus. Pest Manag Sci 70, 173-178, doi:10.1002/ps.3567 (2014).

9 Snelders, E. et al. Possible environmental origin of resistance of Aspergillus fumigatus to medical triazoles. Appl Environ Microbiol 75, 4053-4057, doi:10.1128/AEM.00231-09 (2009).

10 Berger, S., El Chazli, Y., Babu, A. F. \& Coste, A. T. Azole Resistance in Aspergillus fumigatus: A Consequence of Antifungal Use in Agriculture? Front Microbiol 8, 1024, doi:10.3389/fmicb.2017.01024 (2017).

11 Chowdhary, A., Kathuria, S., Xu, J. \& Meis, J. F. Emergence of azole-resistant aspergillus fumigatus strains due to agricultural azole use creates an increasing threat to human health. PLoS Pathog 9, e1003633, doi:10.1371/journal.ppat.1003633 (2013).

12 Moore, C. B. et al. First isolation of the pan-azole-resistant Aspergillus fumigatus cyp51A TR46/Y121F/T289A mutant in a UK patient. Int J Antimicrob Agents 49, 512-514, doi:10.1016/j.ijantimicag.2017.01.004 (2017).

13 van der Linden, J. W. et al. Clinical implications of azole resistance in Aspergillus fumigatus, The Netherlands, 2007-2009. Emerg Infect Dis 17, 1846-1854, doi:10.3201/eid1710.110226 (2011).

14 Wiederhold, N. P. et al. First Detection of TR34 L98H and TR46 Y121F T289A Cyp51 Mutations in Aspergillus fumigatus Isolates in the United States. J Clin Microbiol 54, 168-171, doi:10.1128/JCM.0247815 (2016).

15 Vazquez, J. A. \& Manavathu, E. K. Molecular Characterization of a Voriconazole-Resistant, PosaconazoleSusceptible Aspergillus fumigatus Isolate in a Lung Transplant Recipient in the United States. Antimicrob Agents Chemother 60, 1129-1133, doi:10.1128/AAC.01130-15 (2016).

16 Hurst, S. F., Berkow, E. L., Stevenson, K. L., Litvintseva, A. P. \& Lockhart, S. R. Isolation of azole-resistant Aspergillus fumigatus from the environment in the south-eastern USA. J Antimicrob Chemother 72, 24432446, doi:10.1093/jac/dkx168 (2017).

17 EUCAST. Breakpoint tables for interpretation of MICs meters, version 9.0. (The European Committee on Antimicrobial Susceptibility Testing, 2018).

18 Chowdhary, A., Sharma, C., Kathuria, S., Hagen, F. \& Meis, J. F. Azole-resistant Aspergillus fumigatus with the environmental TR46/Y121F/T289A mutation in India. J Antimicrob Chemother 69, 555-557, doi:10.1093/jac/dkt397 (2014).

19 Pham, C. D., Reiss, E., Hagen, F., Meis, J. F. \& Lockhart, S. R. Passive surveillance for azole-resistant Aspergillus fumigatus, United States, 2011-2013. Emerg Infect Dis 20, 1498-1503, doi:10.3201/eid2009.140142 (2014).

20 Howard, S. J. et al. Frequency and evolution of Azole resistance in Aspergillus fumigatus associated with treatment failure. Emerg Infect Dis 15, 1068-1076, doi:10.3201/eid1507.090043 (2009). 
21 Rivero-Menendez, O., Alastruey-Izquierdo, A., Mellado, E. \& Cuenca-Estrella, M. Triazole Resistance in Aspergillus spp.: A Worldwide Problem? J Fungi (Basel) 2, doi:10.3390/jof2030021 (2016). de Valk, H. A. et al. Use of a novel panel of nine short tandem repeats for exact and high-resolution fingerprinting of Aspergillus fumigatus isolates. J Clin Microbiol 43, 4112-4120, doi:10.1128/JCM.43.8.4112-4120.2005 (2005). Resistant Aspergillus fumigatus in the United States from 2015 to 2017. Antimicrob Agents Chemother 62 , doi:10.1128/AAC.02240-17 (2018).

24 Abdolrasouli, A. et al. Genomic Context of Azole Resistance Mutations in Aspergillus fumigatus Determined Using Whole-Genome Sequencing. mBio 6, e00536, doi:10.1128/mBio.00536-15 (2015).

25 Hobbelen, P. H., Paveley, N. D., Oliver, R. P. \& van den Bosch, F. The usefulness of fungicide mixtures and alternation for delaying the selection for resistance in populations of Mycosphaerella graminicola on winter wheat: a modeling analysis. Phytopathology 103, 690-707, doi:10.1094/PHYTO-06-12-0142-R (2013).

26 FRAC. FRAC recommendations for fungicide mixtures designed to delay resistance evolution. . (Fungicide Resistance Action Committee, 2010). Fall of a Successful Class of Agricultural Fungicides in Fungicides (IntechOpen, 2010). Furtado, L. F. V., de Paiva Bello, A. C. P. \& Rabelo, E. M. L. Benzimidazole resistance in helminths: From problem to diagnosis. Acta Trop 162, 95-102, doi:10.1016/j.actatropica.2016.06.021 (2016). 
TABLE 1. Azole-susceptibility of environmental A. fumigatus isolates with non-synonymous cyp51A mutations.

\begin{tabular}{|c|c|c|c|c|c|}
\hline \multirow[t]{2}{*}{ Isolates } & \multirow[t]{2}{*}{ cyp51A genotype ${ }^{a}$} & \multicolumn{4}{|c|}{ MIC Ranges $(\mu \mathrm{g} / \mathrm{ml})^{b}$} \\
\hline & & TEB & ITC & VOR & POS \\
\hline A1163 & WT & 1.0 & 1.0 & 0.25 & 0.25 \\
\hline eAF221 & $\mathrm{TR}_{46} / \mathrm{Y} 121 \mathrm{~F} / \mathrm{T} 289 \mathrm{~A}$ & $>16$ & $1.0-2.0$ & $>16$ & 1.0 \\
\hline eAF222 & $\mathrm{TR}_{46} / \mathrm{Y} 121 \mathrm{~F} / \mathrm{T} 289 \mathrm{~A}$ & $>16$ & 2.0 & $>16$ & 1.0 \\
\hline eAF228 & $\mathrm{TR}_{46} / \mathrm{Y} 121 \mathrm{~F} / \mathrm{T} 289 \mathrm{~A}$ & $>16$ & $1.0-2.0$ & $>16$ & 1.0 \\
\hline eAF229 & $\mathrm{TR}_{46} / \mathrm{Y} 121 \mathrm{~F} / \mathrm{T} 289 \mathrm{~A}$ & $>16$ & $1.0-2.0$ & $>16$ & 1.0 \\
\hline eAF230 & $\mathrm{TR}_{46} / \mathrm{Y} 121 \mathrm{~F} / \mathrm{T} 289 \mathrm{~A}$ & $>16$ & $1.0-2.0$ & $>16$ & 1.0 \\
\hline eAF231 & $\mathrm{TR}_{46} / \mathrm{Y} 121 \mathrm{~F} / \mathrm{T} 289 \mathrm{~A}$ & $>16$ & $1.0-2.0$ & $>16$ & 1.0 \\
\hline eAF232 & $\mathrm{TR}_{46} / \mathrm{Y} 121 \mathrm{~F} / \mathrm{T} 289 \mathrm{~A}$ & $>16$ & $1.0-2.0$ & $>16$ & 1.0 \\
\hline eAF233 & $\mathrm{TR}_{46} / \mathrm{Y} 121 \mathrm{~F} / \mathrm{T} 289 \mathrm{~A}$ & $>16$ & $1.0-2.0$ & $>16$ & 1.0 \\
\hline eAF234 & $\mathrm{TR}_{46} / \mathrm{Y} 121 \mathrm{~F} / \mathrm{T} 289 \mathrm{~A}$ & $>16$ & $1.0-2.0$ & $>16$ & 1.0 \\
\hline eAF235 & $\mathrm{TR}_{46} / \mathrm{Y} 121 \mathrm{~F} / \mathrm{T} 289 \mathrm{~A}$ & 16 & 1.0 & $\geq 16$ & $0.5-1.0$ \\
\hline eAF236 & $\mathrm{TR}_{46} / \mathrm{Y} 121 \mathrm{~F} / \mathrm{T} 289 \mathrm{~A}$ & $>16$ & $1.0-2.0$ & $>16$ & 1.0 \\
\hline eAF513 & $\mathrm{TR}_{46} / \mathrm{Y} 121 \mathrm{~F} / \mathrm{T} 289 \mathrm{~A}$ & $>16$ & 1.0 & $>16$ & 1.0 \\
\hline eAF010 & $\mathrm{I} 242 \mathrm{~V}$ & $1.0-2.0$ & 1.0 & 0.5 & $0.5-1.0$ \\
\hline eAF175 & I242V & 2.0 & 1.0 & $0.25-0.5$ & 0.5 \\
\hline eAF263 & $\mathrm{I} 242 \mathrm{~V}$ & 2.0 & 1.0 & 0.5 & 0.5 \\
\hline eAF265 & I242V & 2.0 & 1.0 & 0.5 & 0.5 \\
\hline eAF406 & $\mathrm{I} 242 \mathrm{~V}$ & 2.0 & 1.0 & 0.5 & 0.25 \\
\hline eAF500 & I242V & 2.0 & 1.0 & 0.5 & 0.5 \\
\hline eAF589 & $\mathrm{I} 242 \mathrm{~V}$ & 2.0 & 1.0 & $0.25-0.5$ & $0.25-0.5$ \\
\hline eAF621 & $\mathrm{I} 242 \mathrm{~V}$ & 2.0 & 1.0 & 0.5 & 0.5 \\
\hline eAF647 & $\mathrm{I} 242 \mathrm{~V}$ & 2.0 & 1.0 & 0.25 & 0.25 \\
\hline eAF773 & $\mathrm{I} 242 \mathrm{~V}$ & 2.0 & 1.0 & 0.5 & 0.5 \\
\hline eAF792 & $\mathrm{I} 242 \mathrm{~V}$ & $1.0-2.0$ & $0.5-1.0$ & $0.25-0.5$ & $0.25-0.5$ \\
\hline eAF016 & $\begin{array}{l}\text { Y46F/V172M/T248N/ } \\
\text { E255D/K427E }\end{array}$ & $1.0-2.0$ & 1.0 & $0.25-0.5$ & 0.5 \\
\hline eAF082 & $\begin{array}{l}\text { Y46F/V172M/T248N/ } \\
\text { E255D/K427E }\end{array}$ & $1.0-2.0$ & 1.0 & $0.25-0.5$ & $0.25-0.5$ \\
\hline eAF128 & $\begin{array}{l}\text { Y46F/V172M/T248N/ } \\
\text { E255D/K427E }\end{array}$ & 2.0 & 1.0 & 0.5 & 0.5 \\
\hline eAF163 & $\begin{array}{l}\text { Y46F/V172M/T248N/ } \\
\text { E255D/K427E }\end{array}$ & $1.0-2.0$ & 1.0 & $0.25-0.5$ & 0.5 \\
\hline eAF609 & $\begin{array}{l}\text { Y46F/V172M/T248N/ } \\
\text { E255D/K427E }\end{array}$ & $2.0-4.0$ & 1.0 & $0.5-1.0$ & $0.25-0.5$ \\
\hline
\end{tabular}

${ }^{\mathrm{a}}$ Cyp51A protein GenBank accession number EDP50065.1 used as reference. ${ }^{\mathrm{b}}$ MICs, Minimal Inhibitory Concentration; TEB, tebuconazole; ITC, itraconazole; VOR, voriconazole; POS, posaconazole. Each assay was conducted twice. 
TABLE 2. Mutations associated with fungicide resistance in pan-azole-resistant A. fumigatus.

\begin{tabular}{|c|c|c|c|c|}
\hline Isolate & Source & ${\text { cyp } 51 A-\text { azoles }^{\text {a }}}$ & $c y t B-Q_{0 I}^{b}$ & $\operatorname{ben} A-\mathrm{MBC}^{\mathrm{c}}$ \\
\hline A1163 & Clinic & WT & WT & WT \\
\hline eAF222 & $\begin{array}{l}\text { Environment, } 2018 \\
\text { USA }\end{array}$ & $\mathrm{TR}_{46} / \mathrm{Y} 121 \mathrm{~F} / \mathrm{T} 289 \mathrm{~A}$ & G143A & F219Y \\
\hline eAF233 & $\begin{array}{l}\text { Environment, } 2018 \\
\text { USA }\end{array}$ & $\mathrm{TR}_{46} / \mathrm{Y} 121 \mathrm{~F} / \mathrm{T} 289 \mathrm{~A}$ & G143A & $\mathrm{F} 219 \mathrm{Y}$ \\
\hline eAF234 & $\begin{array}{l}\text { Environment, } 2018 \\
\text { USA }\end{array}$ & $\mathrm{TR}_{46} / \mathrm{Y} 121 \mathrm{~F} / \mathrm{T} 289 \mathrm{~A}$ & G143A & F219Y \\
\hline eAF513 & $\begin{array}{l}\text { Environment, } 2018 \\
\text { USA }\end{array}$ & $\mathrm{TR}_{46} / \mathrm{Y} 121 \mathrm{~F} / \mathrm{T} 289 \mathrm{~A}$ & G143A & F219Y \\
\hline $08-12-12-13$ & $\begin{array}{l}\text { Clinic, } 2003 \\
\text { Netherlands }\end{array}$ & $\mathrm{TR}_{34} / \mathrm{L} 98 \mathrm{H} /$ & WT & F219Y \\
\hline 08-31-08-91 & $\begin{array}{l}\text { Clinic, } 2004 \\
\text { Netherlands }\end{array}$ & $\mathrm{TR}_{34} / \mathrm{L} 98 \mathrm{H}$ & WT & F219Y \\
\hline $08-36-03-25$ & $\begin{array}{l}\text { Clinic, } 2005 \\
\text { Netherlands }\end{array}$ & $\mathrm{TR}_{34} / \mathrm{L} 98 \mathrm{H}$ & WT & F219Y \\
\hline $10-01-02-27$ & $\begin{array}{l}\text { Clinic, } 2010 \\
\text { Netherlands }\end{array}$ & $\mathrm{TR}_{34} / \mathrm{L} 98 \mathrm{H}$ & G143A & F219Y \\
\hline Afu 942/09 & $\begin{array}{l}\text { Clinic, } 2009 \\
\text { India }\end{array}$ & $\mathrm{TR}_{34} / \mathrm{L} 98 \mathrm{H}$ & G143A & F219Y \\
\hline Afu 1042/09 & $\begin{array}{l}\text { Clinic, } 2009 \\
\text { India }\end{array}$ & $\mathrm{TR}_{34} / \mathrm{L} 98 \mathrm{H}$ & G143A & F219Y \\
\hline Afu 124/E11 & $\begin{array}{l}\text { Environment, } 2011 \\
\text { India }\end{array}$ & $\mathrm{TR}_{34} / \mathrm{L} 98 \mathrm{H}$ & G143A & F219Y \\
\hline Afu 166/E11 & $\begin{array}{l}\text { Environment, } 2011 \\
\text { India }\end{array}$ & $\mathrm{TR}_{34} / \mathrm{L} 98 \mathrm{H}$ & G143A & F219Y \\
\hline Afu 218/E11 & $\begin{array}{l}\text { Environment, } 2011 \\
\text { India }\end{array}$ & $\mathrm{TR}_{34} / \mathrm{L} 98 \mathrm{H}$ & G143A & F219Y \\
\hline Afu 257/E11 & $\begin{array}{l}\text { Environment, } 2011 \\
\text { India }\end{array}$ & $\mathrm{TR}_{34} / \mathrm{L} 98 \mathrm{H}$ & G143A & F219Y \\
\hline Afu 343/P11 & $\begin{array}{l}\text { Clinic, } 2011 \\
\text { India }\end{array}$ & $\mathrm{TR}_{34} / \mathrm{L} 98 \mathrm{H}$ & G143A & F219Y \\
\hline Afu 591/12 & $\begin{array}{l}\text { Clinic, } 2012 \\
\text { India }\end{array}$ & $\mathrm{TR}_{34} / \mathrm{L} 98 \mathrm{H}$ & G143A & F219Y \\
\hline DI 15-96 & $\begin{array}{l}\text { Clinic, } 2008 \\
\text { USA }\end{array}$ & $\mathrm{TR}_{46} / \mathrm{Y} 121 \mathrm{~F} / \mathrm{T} 289 \mathrm{~A}$ & G143A & F219Y \\
\hline DI 15-102 & $\begin{array}{l}\text { Clinic, } 2010 \\
\text { USA }\end{array}$ & $\mathrm{TR}_{34} / \mathrm{L} 98 \mathrm{H}$ & WT & F219Y \\
\hline DI 15-106 & $\begin{array}{l}\text { Clinic, } 2012 \\
\text { USA }\end{array}$ & $\mathrm{TR}_{46} / \mathrm{Y} 121 \mathrm{~F} / \mathrm{T} 289 \mathrm{~A}$ & G143A & F219Y \\
\hline DI $15-116$ & $\begin{array}{l}\text { Clinic, } 2014 \\
\text { USA }\end{array}$ & $\mathrm{TR}_{34} / \mathrm{L} 98 \mathrm{H}$ & WT & F219Y \\
\hline
\end{tabular}

${ }^{a}$ GenBank accession number EDP50065 from azole-sensitive isolate A1163 was used as wildtype for Cyp51A. Isolates 08-12-12-13 and 08-36-03-25 also carried S297T/F495I mutations for Cyp51A, but these have not been associated with azole resistance. cyp51A TR mutants also carried V13I/I119V mutations for CytB, but these have not been associated with QoI resistance. 


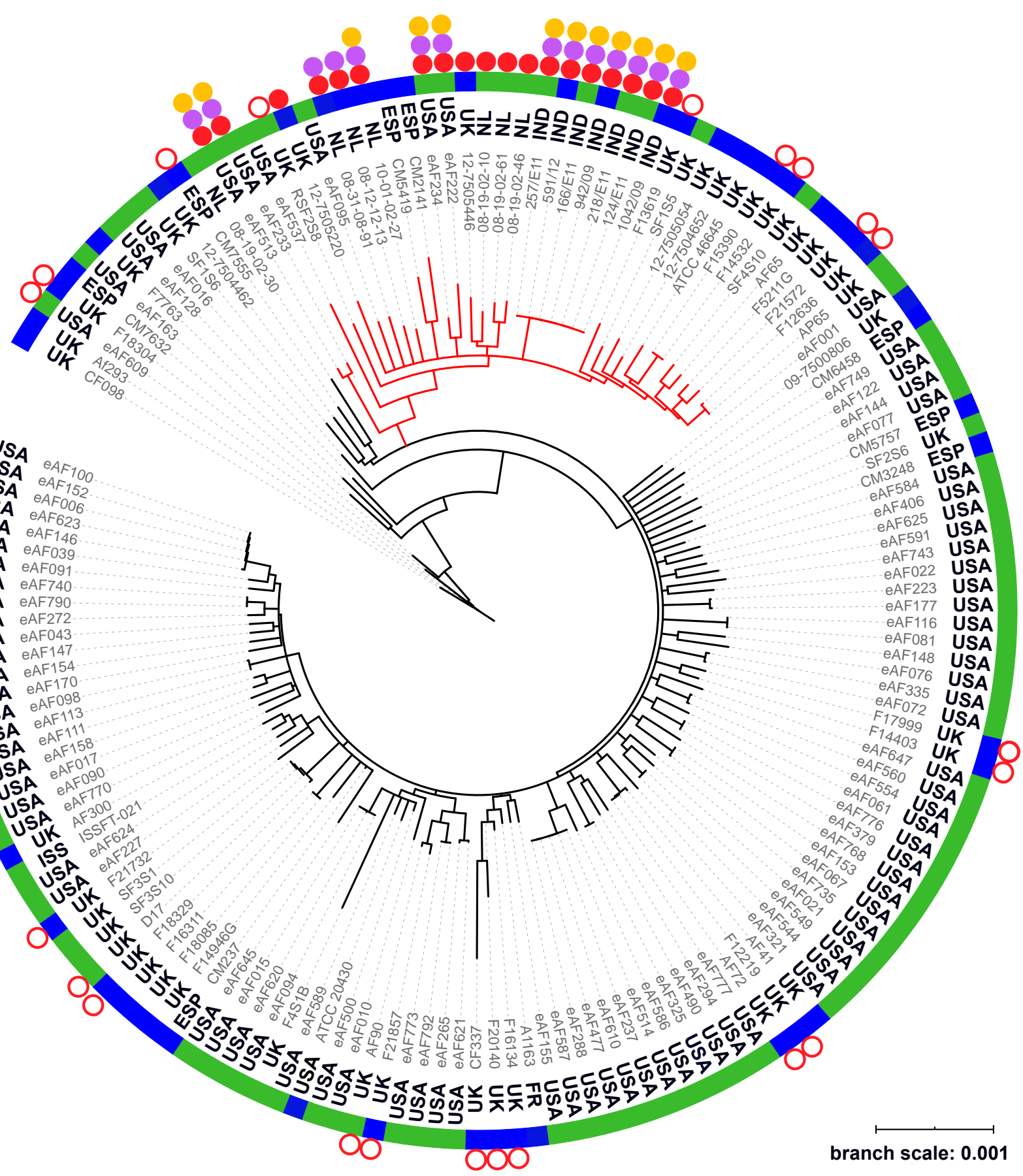

Figure 1. Neighbor-joining tree of environmental and clinical isolates of Aspergillus fumigatus. Whole genome sequences from Georgia and Florida agricultural sites (this study, eAFXXX), were analyzed along with publicly available data (Table S3). Af293 was used as the reference genome. Country of origin is listed next to each isolate (ESP=Spain, FR=France, IND=India, ISS=International Space Station, NL=Netherlands, UK=United Kingdom, USA=United States). Only branches with $100 \%$ bootstrap support based on 100 replicates are shown. Green bars indicate environmental isolates. Blue bars indicate clinical isolates. Solid red circles indicate pan-azole-resistant isolates with cyp51A TR mutations. Open red circles indicate azole-resistant isolates without TR mutations. Orange circles indicate isolates with $c y t B$ G143A mutation conferring resistance to QoI fungicides. Violet circles indicate benA F219Y mutation conferring resistance to MBC fungicides. Red branches indicate well-supported pan-azoleresistant clade. 


\section{Methods}

\section{Sampling}

Between July 2017 and March 2018 we collected soil, plant debris, or compost from 56 agricultural sites in Georgia or Florida, USA, including 53 sites that had recently been treated with triazole fungicides, two sites that were in organic production with no triazole use in at least 10 years, and one compost pile with an unknown history of fungicide use on the plant material prior to composting (Supplementary Table S1). Each site was defined as a different field location, different crop at the same field location, or different triazole fungicide treatment. When soil was sampled, plant debris on the soil surface was included if available. If larger piles of debris were present on the soil surface they were collected separately. Soil was sampled by taking 5-10 soil cores to a depth of approximately 10 $\mathrm{cm}$. Plant debris was sampled from the soil surface, cull piles at farms, and waste piles at pecan processing facilities. For each site we collected 4 samples at separate locations to minimize the collection of clones. Samples were stored in sealed plastic bags for transport and stored open to allow for gas exchange at $4{ }^{\circ} \mathrm{C}$ for $2-20 \mathrm{~d}$.

\section{Isolation and storage}

The samples were processed as described previously by Snelder et al. ${ }^{9}$ and Hurst et al. ${ }^{16}$ with some modifications. Briefly, $2 \mathrm{~g}$ of soil was suspended in $15 \mathrm{ml}$ of sterile $0.1 \mathrm{M}$ sodium pyrophosphate. Samples were vortexed for $30 \mathrm{~s}$ and allowed to settle for $1 \mathrm{~min}$. From the supernatant, $100 \mu \mathrm{l}$ was pipetted onto Sabouraud dextrose agar (SDA) in 100-mm Petri dishes supplemented with $50 \mu \mathrm{g} / \mathrm{ml}$ chloramphenicol (Sigma Aldrich) and $5 \mu \mathrm{g} / \mathrm{ml}$ gentamicin (Research Products International). The dishes were incubated for 2 to $4 \mathrm{~d}$ at $45^{\circ} \mathrm{C}$. Colonies of $A$. fumigatus were initially identified based on morphology and screened for azole resistance on SDA supplemented with $3 \mu \mathrm{g} / \mathrm{ml}$ tebuconazole (TEB; Bayer Corp). Many of the isolates that grew on $3 \mu \mathrm{g} / \mathrm{ml} \mathrm{TEB}$-amended solid medium were not able to grow at similar concentrations of TEB in liquid medium during the MIC testing described below; therefore, these isolates are designated as sensitive to TEB in Supplementary Table S1. Isolates were stored at $-80^{\circ} \mathrm{C}$ in $15 \%$ glycerol.

\section{Antifungal susceptibility testing by Minimum Inhibitory Concentrations (MIC)}

One hundred-seventy-two environmental A. fumigatus isolates (Supplementary Table S1), and 48 clinical isolates were tested for antifungal susceptibility under conditions described in the Clinical Laboratory Standard Institute broth microdilution method ${ }^{29}$. Antifungals tested included tebuconazole (TEB; TCI America, Oregon, USA), itraconazole (ITC; Thermo Sci Acros Organics, New Jersey, USA), voriconazole (VOR; Thermo Sci Acros Organics, New Jersey, USA), and posaconazole (POS; Apexbio Technology, Texas, USA) suspended in DMSO. Briefly, isolates were grown on complete media ${ }^{30}$ slants for 5 to $7 \mathrm{~d}$ at $37^{\circ} \mathrm{C}$ and harvested with $2 \mathrm{ml}$ of $0.02 \%$ Tween-20 solution. Spore suspensions were adjusted to $0.09-0.13 \mathrm{OD}$ at $530 \mathrm{~nm}$ using a spectrophotometer. One-hundred microliters of $2 \times 10^{4}$ to $5 \times 10^{4}$ conidia/ml were added to $100 \mathrm{ml}$ of RPMI 1640 liquid medium (Thermo Sci Gibco, California, USA) in microtiter plates with final concentrations of antifungals ranging from 0.015 to $16 \mu \mathrm{g} / \mathrm{ml}$. Plates were incubated at $37^{\circ} \mathrm{C}$ for $48 \mathrm{~h}$ and MIC break points were determined visually. MIC break point was defined as the lowest concentration at which there was $100 \%$ inhibition of growth. Assays were repeated for all resistant isolates and most sensitive isolates. For classification of sensitivity or resistance for ITC and VOR, we used the recommended clinical breakpoints of antifungal resistance for A. fumigatus ${ }^{17}$ which are $>2 \mu \mathrm{g} / \mathrm{ml}$; however, EUCAST notes there is uncertainty regarding the cutoff values for POS and some data suggest $>1 \mu \mathrm{g} / \mathrm{ml}$, which we use here, may be more relevant.

\section{DNA extraction}

High molecular weight genomic DNA of A. fumigatus isolates was extracted using a modified CTAB protocol as described previously ${ }^{31}$. Briefly, approximately $100 \mathrm{mg}$ of mycelium collected from cultures that had been incubated overnight in liquid complete medium ${ }^{30}$ were transferred to $2 \mathrm{ml}$ tubes containing approximately $200 \mu \mathrm{of} 0.5-\mathrm{mm}$ disruption glass beads (RPI, catalog \#9831) and three 3-mm steel beads and lyophilized. Lyophilized cells were pulverized using Geno/Grinder at $1750 \mathrm{rpm}$ for $30 \mathrm{~s}$. Pulverized tissue was incubated in $1 \mathrm{ml}$ of CTAB lysis buffer (100 mM Tris $\mathrm{pH} 8.0,10 \mathrm{mM}$ EDTA, $1 \% \mathrm{CTAB}, 1 \% \mathrm{BME}$ ) for $30 \mathrm{~min}$ at $65^{\circ} \mathrm{C}$. The samples were extracted with chloroform $(500 \mu \mathrm{l})$ twice and DNA in the upper layer was precipitated in ice cold isopropanol. The precipitated DNA samples were washed with $70 \%$ ethanol twice, air dried, and dissolved in $100 \mu \mathrm{l}$ sterile water. DNA was quantified using NanoDrop One (Thermo Sci, New Jersey, USA). 
306

307

308

309

310

311

312

313

314

315

316

317

318

319

320

321

322

323

324

325

326

327

328

329

330

331

332

333

334

335

336

337

338

339

340

341

342

343

344

345

346

347

348

349

350

351

352

353

354

355

356

357

358

359

\section{cyp51A sequencing}

For all environmental isolates in this study, cyp51A was PCR-amplified using previously designed primers ${ }^{32}$. PCR reactions were performed with the Q5 Hot Start High-Fidelity 2× Master Mix (New England Biolabs) with $100 \mathrm{ng}$ of genomic DNA, $0.5 \mu \mathrm{M}$ forward primer 5' -CGGGCTGGAGATACTATGGCT-3' and $0.5 \mu \mathrm{M}$ reverse primer 5' GTATAATACACCTATTCCGATCACACC- $3^{\prime}$ in $20 \mu$ reactions. PCR reactions were performed at $98^{\circ} \mathrm{C}$ for $2 \mathrm{~min}$ followed by 30 cycles of $98^{\circ} \mathrm{C}$ for $15 \mathrm{~s}, 62^{\circ} \mathrm{C}$ for $15 \mathrm{~s}$, and $72^{\circ} \mathrm{C}$ for $2: 30 \mathrm{~min}$, followed by a final extension at $72^{\circ} \mathrm{C}$ for $5 \mathrm{~min}$. Amplicons were sequenced by the Sanger method (Eurofins genomics, USA) using primers $5^{\prime}$ GCATTCTGAAACACGTGCGTAG-3', 5'-GTCTCCTCGAAATGGTGCCG-3', and 5'-

CGTTCCAAACTCACGGCTGA-3'. Promoter sequences were aligned to A1163 genomic sequence v43 from Ensembl. Coding sequences were translated to protein sequences and aligned to the Cyp51A protein of A. fumigatus A1163 (GenBank accession EDP50065). Sequence analysis was performed using Geneious v11.1.5 (Biomatters, Auckland, NZ).

\section{Microsatellite genotyping}

Nine microsatellite markers (STRAf 2A, 2B, 2C, 3A, 3B, 3C, 4A, 4B, and 4C) previously developed for A. fumigatus (de Valk et al. 2005) were used to genotype 166 environmental isolates (Supplementary Table 1), the reference isolate Af293, and 48 clinical isolates from Georgia or Florida provided by the Mycotic Diseases Group at CDC ${ }^{23}$. Multiplex PCR was performed using the Type-it Microsatellite PCR kit (Qiagen) following the manufacturer's protocol, but with the reaction volume modified to $10 \mu \mathrm{l}$. Multiplex reactions contained the following: $5 \mu 1$ of $2 \times$ Type-it Master Mix, $1 \mu \mathrm{l}$ of $10 \times$ primer mix ( $2 \mu \mathrm{M}$ of each primer in the multiplex), $1 \mu \mathrm{l}$ of DNA template, and RNAse-free water. Thermal cycling conditions had an initial denaturation at $95^{\circ} \mathrm{C}$ for 5 min followed by: 28 cycles of $95^{\circ} \mathrm{C}$ for $30 \mathrm{~s}, 57^{\circ} \mathrm{C}$ for $90 \mathrm{~s}$, and $72^{\circ} \mathrm{C}$ for $30 \mathrm{~s}$ and a final elongation of $60^{\circ} \mathrm{C}$ for $30 \mathrm{~min}$. Amplification of a product was confirmed by electrophoresis on a $1 \%(\mathrm{w} / \mathrm{v})$ agarose gel with $1 \times \mathrm{TBE}$ buffer. PCR products were diluted (1:15) then $1 \mu \mathrm{l}$ of diluted PCR product was added with $0.1 \mu \mathrm{l}$ of the internal size standard Genescan-500 Liz (Applied Biosystems) and $9.9 \mu \mathrm{l}$ of Hi-Di formamide (Applied Biosystems). These were then incubated for $5 \mathrm{~min}$ at $95^{\circ} \mathrm{C}$ and placed immediately on ice. Fragment analysis was performed at the Georgia Genomics and Bioinformatics Core (GGBC) on an Applied Biosystems 3730x1 96-capillary DNA analyzer. Microsatellite Plugin in Geneious v.6 (Biomatters) was used to score alleles and loci were distinguished based on expected size range. To examine relationships among all isolates and isolates from different environments, a minimum spanning network was constructed using the Bruvo's genetic distance model ${ }^{33}$ in the Poppr package executed in $\mathrm{R}^{34}$.

\section{Library preparation and whole genome sequencing}

Genomic DNA was sheared to a mean size of 600 bp using a Covaris LE220 focused ultrasonicator (Covaris Inc., Woburn, MA). DNA fragments were Ampure (Beckman Coulter Inc., Indianapolis, IN) cleaned and used to prepare dual-indexed sequencing libraries using NEBNext Ultra library prep reagents (New England Biolabs Inc., Ipswich, MA) and barcoding indices synthesized in the CDC Biotechnology Core Facility. Libraries were analyzed for size and concentration, pooled and denatured for loading onto flowcell for cluster generation. Sequencing was performed on an Illumina Hiseq using 300×300 cycle paired-end sequencing kit. On completion, sequence reads were filtered for read quality, base called and demultiplexed using Casava v1.8.4. All raw reads and assemblies were deposited in GenBank under project \#XXXXXX.

\section{SNP calling and neighbor-joining tree}

Cleaned whole genome sequence reads for each isolate were de novo assembled using SPAdes v3.12.0 ${ }^{35}$ with option --careful and trained to Af293 reference genome ${ }^{36}$ using option --trusted-contigs. Corrected fasta files generated from SPAdes were aligned to Af293 reference genome using Burrows-Wheeler Aligner (BWA) alignment tool ${ }^{37}$ and duplicate reads were marked using Picard v2.16.0. Single nucleotide polymorphisms (SNPs) were called with SAMtools mpileup v1.6 $6^{37}$ with option - I to exclude insertions and deletions then with BCFtools v1.9 with option $-\mathrm{c}$. Bases with phred quality score lower than 40 were filtered using SAMtools seqtk v1.2. SNP data were converted into interleaved phylip format and a neighbor-joining tree was constructed using Seaview v4. $7^{38}$. Support for internal branches was determined by 100 bootstrap replicates. The tree was visualized and annotated using iTOL: International Tree of Life $v 5^{39}$. 
Genome mining for agricultural fungicide resistance

\section{References (for Methods)}

29 CLSI. Reference method for broth dilution antifungal susceptibility testing of filamentous fungi; approved standard. Vol. CLSI document M38-A2. (2008).

30 Momany, M., Westfall, P. J. \& Abramowsky, G. Aspergillus nidulans swo mutants show defects in polarity establishment, polarity maintenance and hyphal morphogenesis. Genetics 151, 557-567 (1999).

31 Pitkin, J. W., Panaccione, D. G. \& Walton, J. D. A putative cyclic peptide efflux pump encoded by the TOXA gene of the plant-pathogenic fungus Cochliobolus carbonum. Microbiology 142 ( Pt 6), 1557-1565, doi:10.1099/13500872-142-6-1557 (1996).

32 Mellado, E., Diaz-Guerra, T. M., Cuenca-Estrella, M. \& Rodriguez-Tudela, J. L. Identification of two different 14-alpha sterol demethylase-related genes (cyp51A and cyp51B) in Aspergillus fumigatus and other Aspergillus species. J Clin Microbiol 39, 2431-2438, doi:10.1128/JCM.39.7.2431-2438.2001 (2001).

33 Bruvo, R., Michiels, N. K., D'Souza, T. G. \& Schulenburg, H. A simple method for the calculation of microsatellite genotype distances irrespective of ploidy level. Mol Ecol 13, 2101-2106, doi:10.1111/j.1365294X.2004.02209.x (2004).

34 Kamvar, Z. N., Tabima, J. F. \& Grunwald, N. J. Poppr: an R package for genetic analysis of populations with clonal, partially clonal, and/or sexual reproduction. PeerJ 2, e281, doi:10.7717/peerj.281 (2014).

35 Nurk, S. Assembling Genomes and Mini-metagenomes from Highly Chimeric Reads in Research in Computational Molecular Biology. RECOMB 2013. Lecture Notes in Computer Science Vol. 7821 (eds M. Deng, R. Jiang, F. Sun, \& X. Zhang) (Springer, 2013).

36 Nierman, W. C. et al. Genomic sequence of the pathogenic and allergenic filamentous fungus Aspergillus fumigatus. Nature 438, 1151-1156, doi:10.1038/nature04332 (2005).

37 Li, H. et al. The Sequence Alignment/Map format and SAMtools. Bioinformatics 25, 2078-2079, doi:10.1093/bioinformatics/btp352 (2009).

38 Gouy, M., Guindon, S. \& Gascuel, O. SeaView version 4: A multiplatform graphical user interface for sequence alignment and phylogenetic tree building. Mol Biol Evol 27, 221-224, doi:10.1093/molbev/msp259 (2010).

39 Letunic, I. \& Bork, P. Interactive Tree Of Life (iTOL) v4: recent updates and new developments. Nucleic Acids Res 47, W256-W259, doi:10.1093/nar/gkz239 (2019).

40 Altschul, S. F., Gish, W., Miller, W., Myers, E. W. \& Lipman, D. J. Basic local alignment search tool. J Mol Biol 215, 403-410, doi:10.1016/S0022-2836(05)80360-2 (1990).

41 Vega, B., Liberti, D., Harmon, P. F. \& Dewdney, M. M. A Rapid Resazurin-Based Microtiter Assay to Evaluate QoI Sensitivity for Alternaria alternata Isolates and Their Molecular Characterization. Plant Dis 96, 1262-1270, doi:10.1094/PDIS-12-11-1037-RE (2012).

42 Summerbell, R. C. The benomyl test as a fundamental diagnostic method for medical mycology. J Clin Microbiol 31, 572-577 (1993) 


\section{Acknowledgements}

Research was funded by the Centers for Disease Control and Prevention (CDC; contract 200-2017-96199 to M.M. and M.T.B.) and the University of Georgia (President's Interdisciplinary Seed Grant to M.T.B and M.M.). We thank the Mycotic Diseases Branch and Elizabeth Berkow at CDC for guidance and clinical isolates from Georgia and Florida. We thank Megan Dewdney, Gary Vallad, and Katia Xavier from the University of Florida, and Bhabesh Dutta, Robert Kemerait, Albert Culbreath, Tim Brenneman, Renee Allen, and Elizabeth Little from the University of Georgia for assistance collecting environmental samples. We thank Douda Bensasson from the University of Georgia for advice and insight on phylogenetic analysis.

\section{Author Contributions}

S.E.K., M.T.B., and M.M. conceived and designed the research. S.E.K., T.M., L.G.S., and B.M. conducted the experiments. S.E.K., M.T.B., and L.G.S. collected environmental samples. S.E.K., T.M., L.G.S., B.M., M.M. and M.T.B analyzed the data. S.E.K., M.M. and M.T.B. wrote the manuscript with contributions from all authors.

Competing interests The authors declare no competing interests.

Materials requests \& Correspondence should be addressed to M.T.B. or M.M. 
433 SUPPLEMENTARY TABLE S1. Sampling of $A$. fumigatus strains from agricultural sites

\begin{tabular}{|c|c|c|c|c|c|c|c|}
\hline \multirow[b]{2}{*}{$\begin{array}{l}\text { Crop and/or } \\
\text { substrate } \\
\text { sampled }^{\mathrm{a}}\end{array}$} & \multirow[b]{2}{*}{$\begin{array}{l}\text { Location(s) } \\
\text { sampled }\end{array}$} & \multirow{2}{*}{$\begin{array}{l}\text { Sampling } \\
\text { date(s) } \\
\text { MM/DD/YY } \\
\left(\text { no. sites }{ }^{\text {b }}\right) \\
\end{array}$} & \multirow{2}{*}{$\begin{array}{l}\text { Isolates } \\
\text { collected, } \\
\text { no. grew on } \\
\text { TEB- } \\
\text { amended } \\
\text { plates }\end{array}$} & \multicolumn{2}{|c|}{$\mathrm{MIC}^{\mathrm{c}}$} & \multirow[b]{2}{*}{$\begin{array}{l}\text { WGS strains } \\
\text { (*azole- } \\
\text { resistant) }\end{array}$} & \multirow{2}{*}{$\begin{array}{l}\text { No. isolates } \\
\text { genotyped } \\
\text { at } \text { cyp51A } \\
\text { \& STR } A f^{\mathrm{e}}\end{array}$} \\
\hline & & & & Sensitive & $\begin{array}{l}\text { Resistant } \\
\text { (MIC } \\
\text { values) }\end{array}$ & & \\
\hline $\begin{array}{l}\text { Apple } \\
\text { (soil \& plant } \\
\text { debris) }\end{array}$ & Union Co., GA & $08 / 21 / 17(1)$ & 9,4 & 5 & 0 & eAF76, eAF77 & 5 \\
\hline Blueberry & Clinch Co., GA & $01 / 17 / 18(3)$ & 1,0 & 1 & 0 & eAF584 & 0 \\
\hline $\begin{array}{l}\text { (soil \& plant } \\
\text { debris) }\end{array}$ & Bacon Co., GA & $01 / 18 / 18(2)$ & 16,0 & 2 & 0 & & 1 \\
\hline $\begin{array}{l}\text { Citrus } \\
\text { (soil \& plant } \\
\text { debris) }\end{array}$ & Polk Co., FL & $03 / 28 / 18(13)$ & 64,8 & 11 & 0 & $\begin{array}{l}\text { eAF735, } \\
\text { eAF743, } \\
\text { eAF749, } \\
\text { eAF768, } \\
\text { eAF770, } \\
\text { eAF773, } \\
\text { eAF776, } \\
\text { eAF777, } \\
\text { eAF790, } \\
\text { eAF792 }\end{array}$ & 10 \\
\hline Watermelon & Crisp Co., GA & $06 / 07 / 17$ (1) & 3,0 & 1 & 0 & eAF1 & 1 \\
\hline $\begin{array}{l}\text { (soil \& plant } \\
\text { debris) }\end{array}$ & $\begin{array}{l}\text { Hillsborough } \\
\text { Co., FL }\end{array}$ & $03 / 27 / 18$ (1) & 2,2 & 1 & 0 & eAF740 & 1 \\
\hline Watermelon & Crisp Co., GA & 07/07/17 (1) & 0,0 & 0 & 0 & eAF6, eAF10, & 0 \\
\hline (soil \& plant & & 08/01/17 (1) & 18,7 & 9 & 0 & eAF15, eAF16, & 9 \\
\hline debris) & & 08/27/17 (1) & 34,24 & 25 & 0 & $\begin{array}{l}\text { eAF17, eAF39, } \\
\text { eAF43 }\end{array}$ & 25 \\
\hline Compost pile & Clarke Co., GA & $12 / 06 / 17(1)$ & 22,12 & 2 & $\begin{array}{c}11(1 \mathrm{TEB} \\
\& \mathrm{VOR}= \\
16 \\
\mu \mathrm{g} / \mathrm{mL} ; 10 \\
\mathrm{TEB} \& \\
\mathrm{VOR}>16 \\
\mu \mathrm{g} / \mathrm{mL})\end{array}$ & $\begin{array}{l}\text { eAF222*, } \\
\text { eAF223, } \\
\text { eAF227, } \\
\text { eAF233*, } \\
\text { eAF234* }\end{array}$ & 13 \\
\hline $\begin{array}{l}\text { Grape } \\
\text { (soil \& plant } \\
\text { debris) }\end{array}$ & Union Co., GA & $08 / 21 / 17$ (1) & 14,7 & 9 & 0 & $\begin{array}{l}\text { eAF21, eAF22, } \\
\text { eAF61, eAF67, } \\
\text { eAF72 }\end{array}$ & 9 \\
\hline $\begin{array}{l}\text { Tomato } \\
\text { (soil \& plant } \\
\text { debris) }\end{array}$ & $\begin{array}{l}\text { Hillsborough } \\
\text { Co., FL }\end{array}$ & $03 / 27 / 18(3)$ & 35,3 & 7 & 0 & $\begin{array}{l}\text { eAF620, } \\
\text { eAF621, } \\
\text { eAF623, } \\
\text { eAF624, } \\
\text { eAF625, } \\
\text { eAF645, } \\
\text { eAF647 }\end{array}$ & 7 \\
\hline $\begin{array}{l}\text { Strawberry } \\
\text { (soil \& plant } \\
\text { debris) }\end{array}$ & $\begin{array}{l}\text { Hillsborough } \\
\text { Co., FL }\end{array}$ & $03 / 27 / 18(1)$ & 25,3 & 5 & $\begin{array}{l}1(\mathrm{TEB}= \\
4 \mu \mathrm{g} / \mathrm{mL})\end{array}$ & $\begin{array}{l}\text { eAF586, } \\
\text { eAF587, } \\
\text { eAF589, } \\
\text { eAF591, } \\
\text { eAF609*, } \\
\text { eAF610 }\end{array}$ & 6 \\
\hline $\begin{array}{l}\text { Peanut } \\
\text { (soil \& plant } \\
\text { debris) }\end{array}$ & Tift Co., GA & $10 / 20 / 17(6)$ & 28,18 & 22 & 0 & $\begin{array}{l}\text { eAF90, eAF91, } \\
\text { eAF94, eAF95, } \\
\text { eAF111, }\end{array}$ & 22 \\
\hline
\end{tabular}




\begin{tabular}{|c|c|c|c|c|c|c|c|}
\hline & & & & & & $\begin{array}{l}\text { eAF113, } \\
\text { eAF144, } \\
\text { eAF148, } \\
\text { eAF152, } \\
\text { eAF153, } \\
\text { eAF154, }\end{array}$ & \\
\hline $\begin{array}{l}\text { Peanut } \\
\text { (plant debris) }\end{array}$ & $\begin{array}{l}\text { Tift Co., GA } \\
\text { Turner Co., GA }\end{array}$ & $\begin{array}{l}10 / 20 / 17(4) \\
10 / 20 / 17(1)\end{array}$ & $\begin{array}{c}59,27 \\
4,2\end{array}$ & $\begin{array}{c}33 \\
3\end{array}$ & $\begin{array}{l}0 \\
0\end{array}$ & $\begin{array}{l}\text { eAF81, eAF98, } \\
\text { eAF100, } \\
\text { eAF105, } \\
\text { eAF116, } \\
\text { eAF122, } \\
\text { eAF128, } \\
\text { eAF146, } \\
\text { eAF147, } \\
\text { eAF155, } \\
\text { eAF158, } \\
\text { eAF163, } \\
\text { eAF177, } \\
\text { eAF170 }\end{array}$ & $\begin{array}{c}32 \\
3\end{array}$ \\
\hline $\begin{array}{l}\text { Pecan } \\
\text { (plant debris; } \\
\text { two sites } \\
\text { were } \\
\text { processing } \\
\text { facilities) }\end{array}$ & $\begin{array}{l}\text { Dougherty Co., } \\
\text { GA }\end{array}$ & 12/13/17 (11) & 294,6 & 19 & $\begin{array}{c}1 \text { (TEB \& } \\
\text { VOR MIC } \\
>16 \\
\mu \mathrm{g} / \mathrm{mL})\end{array}$ & $\begin{array}{l}\text { eAF263, } \\
\text { eAF265, } \\
\text { eAF272, } \\
\text { eAF288, } \\
\text { eAF321, } \\
\text { eAF325, } \\
\text { eAF365, } \\
\text { eAF379, } \\
\text { eAF406, } \\
\text { eAF477, } \\
\text { eAF490, } \\
\text { eAF500, } \\
\text { eAF513*, } \\
\text { eAF514, } \\
\text { eAF537, } \\
\text { eAF544, } \\
\text { eAF549, } \\
\text { eAF554, } \\
\text { eAF560 }\end{array}$ & 19 \\
\hline $\begin{array}{l}\text { Pecan } \\
\text { (soil \& plant } \\
\text { debris) }\end{array}$ & $\begin{array}{l}\text { Dougherty Co., } \\
\text { GA }\end{array}$ & $12 / 13 / 17(2)$ & 28,0 & 2 & 0 & $\begin{array}{l}\text { eAF294, } \\
\text { eAF335 }\end{array}$ & 2 \\
\hline $\begin{array}{l}\text { Organic } \\
\text { cucurbits } \\
\text { (soil \& plant } \\
\text { debris) }\end{array}$ & Oconee Co., GA & $12 / 06 / 17(1)$ & 28,0 & 1 & 0 & & 0 \\
\hline $\begin{array}{l}\text { Organic } \\
\text { brassicas } \\
\text { (soil \& plant } \\
\text { debris) }\end{array}$ & Clarke Co., GA & $12 / 06 / 17(1)$ & 16,0 & 1 & 0 & eAF237 & 1 \\
\hline Total & & 56 sites & 700,123 & 159 & 13 & 92 & 166 \\
\hline
\end{tabular}

${ }^{\text {a}}$ Four samples were collected from distinct locations at each site; soil \& plant debris indicates that soil was sampled and decaying plant debris on the soil surface was included in the sample.

${ }^{b}$ Each site was defined as a different field location, different crop at the same field location, or different triazole fungicide treatment

${ }^{\mathrm{c}}$ All strains that grew on the TEB-amended medium were assayed for MIC. Additionally, 1 or 2 strains per site that did not grow on the amended medium were assayed for MIC for comparison. Isolates were considered resistant if TEB, ITC or VOR MIC values were $>2 \mu \mathrm{g} / \mathrm{mL}$, or POS $>1 \mu \mathrm{g} / \mathrm{mL}$; otherwise they were considered sensitive. MIC 
442

443

444

445

446

447

448

449

450

451

452

453

454

455

456

457

458

459

460

461

462

assays were conducted twice for all resistant isolates and most sensitive isolates. Most often, there was no variation between replicates, but if there was a difference, the greater MIC is presented here.

${ }^{\mathrm{d}}$ For whole genome sequencing (WGS) and phylogenetic analyses, 1 strain that grew and 1 strain that did not grow on TEB-amended medium that had been assayed for MIC were analyzed per site. WGS from three isolates (eAF105, eAF263, eAF365) were not included in the NJ tree due to excessive missing data.

${ }^{\mathrm{e}}$ cyp51A genotypes were analyzed from all WGS strains and cyp51A genotypes for all remaining strains that grew on TEB-amended medium were analyzed by PCR and Sanger sequencing. All strains were genotyped with STR $A f$ microsatellite markers.

SUPPLEMENTARY TABLE S2. Minimum inhibitory concentrations (MIC) $)^{\text {a }}$ for A. fumigatus $(n=172)$ isolated from agricultural environments in Georgia and Florida where azole fungicides were applied.

\begin{tabular}{|c|c|c|c|c|c|c|c|c|c|}
\hline \multirow[t]{2}{*}{ Azole } & \multicolumn{9}{|c|}{ Final Drug Concentration $(\mu \mathrm{g} / \mathrm{mL})$} \\
\hline & $>16$ & 16 & 8 & 4 & 2 & 1 & 0.5 & 0.25 & $<0.25$ \\
\hline Tebuconazole & 11 & 1 & & 1 & 85 & 68 & 6 & & \\
\hline Itraconazole & & & & & 11 & 140 & 21 & & \\
\hline Voriconazole & 12 & & & & & 1 & 81 & 72 & 6 \\
\hline Posaconazole & & & & & & 15 & 93 & 58 & 6 \\
\hline
\end{tabular}

${ }^{a}$ Isolates were assayed for MIC once (some sensitive isolates) or twice (all resistant and some sensitive isolates). Most often, there was no variation between replicates, but if there was a difference, the greater MIC is presented here.

SUPPLEMENTARY TABLE S3. Publicly available genome sequence data used in this study for neighbor-joining tree and mining for antifungal-resistance genes and mutations (italics)

\begin{tabular}{|l|l|l|l|l|l|}
\hline $\begin{array}{l}\text { NCBI_SRA_ } \\
\text { ID }\end{array}$ & Taxa_ID & $\begin{array}{l}\text { Sampling } \\
\text { Location }\end{array}$ & $\begin{array}{l}\text { Environ (E) } \\
\text { /Clinical } \\
(\mathbf{C})\end{array}$ & $\begin{array}{l}\text { Azole-Res } \\
(\mathbf{R}) \\
\text { /Sens(S) }\end{array}$ & Reference \\
\hline ERR769506 & $08-12-12-13$ & Netherlands & C & R & $\begin{array}{l}\text { doi: } 10.1128 / \mathrm{mBio} .00536- \\
15\end{array}$ \\
\hline ERS663179 & $08-19-02-10$ & Netherlands & E & R & $\begin{array}{l}\text { doi: } 10.1128 / \mathrm{mBio.00536-} \\
15\end{array}$ \\
\hline ERS663176 & $08-19-02-30$ & Netherlands & E & S & $\begin{array}{l}\text { doi: } 10.1128 / \mathrm{mBio.00536-} \\
15\end{array}$ \\
\hline ERR769512 & $08-19-02-46$ & Netherlands & E & R & $\begin{array}{l}\text { doi: } 10.1128 / \mathrm{mBio.00536-} \\
15\end{array}$ \\
\hline ERR769509 & $08-19-02-61$ & Netherlands & E & R & $\begin{array}{l}\text { doi: } 10.1128 / \mathrm{mBio.00536-} \\
15\end{array}$ \\
\hline ERR769508 & $08-31-08-91$ & Netherlands & C & R & $\begin{array}{l}\text { doi: } 10.1128 / \mathrm{mBio.00536-} \\
15\end{array}$ \\
\hline ERS663166 & $09-7500806$ & UK & C & S & $\begin{array}{l}\text { doi: } 10.1128 / \mathrm{mBio.00536-} \\
15\end{array}$ \\
\hline ERR769511 & $10-01-02-27$ & Netherlands & C & R & $\begin{array}{l}\text { doi: } 10.1128 / \mathrm{mBio.00536-} \\
15\end{array}$ \\
\hline ERS663168 & $12-7504462$ & UK & C & S & $\begin{array}{l}\text { doi: } 10.1128 / \mathrm{mBio.00536-} \\
15\end{array}$ \\
\hline ERS663167 & $12-7504652$ & UK & C & S & $\begin{array}{l}\text { doi: } 10.1128 / \mathrm{mBio.00536-} \\
15\end{array}$ \\
\hline
\end{tabular}




\begin{tabular}{|c|c|c|c|c|c|}
\hline ERS663169 & $12-7505054$ & UK & $\mathrm{C}$ & $S$ & $\begin{array}{l}\text { doi: } 10.1128 / m B i o .00536- \\
15\end{array}$ \\
\hline ERS663165 & $12-7505220$ & UK & $\mathrm{C}$ & $\mathrm{R}$ & $\begin{array}{l}\text { doi: } 10.1128 / m B i o .00536- \\
15\end{array}$ \\
\hline ERS663164 & $12-7505446$ & UK & $\mathrm{C}$ & $\mathrm{R}$ & $\begin{array}{l}\text { doi: } 10.1128 / m B i o .00536- \\
15\end{array}$ \\
\hline ERR232426 & A1163 & France & $\mathrm{C}$ & $S$ & NCBI SRA \\
\hline ERS663170 & Af293 & UK & $\mathrm{C}$ & $S$ & $\begin{array}{l}\text { doi: } 10.1128 / \mathrm{mBio} .00536- \\
15\end{array}$ \\
\hline ERX207014 & AF300 & UK & $\mathrm{C}$ & $S$ & NCBI SRA \\
\hline SRS375791 & AF41 & UK & $\mathrm{C}$ & $S$ & NCBI SRA \\
\hline ERS663171 & AF65 & UK & $\mathrm{C}$ & $\mathrm{S}$ & $\begin{array}{l}\text { doi: } 10.1128 / \mathrm{mBio} .00536- \\
15\end{array}$ \\
\hline SRR617721 & AF72 & UK & $\mathrm{C}$ & $\mathrm{R}$ & $\begin{array}{l}\text { doi: } \\
\text { 10.1128/AAC.41.6.1364 }\end{array}$ \\
\hline SRR617722 & AF90 & UK & $\overline{\mathrm{E}}$ & $\mathrm{R}$ & $\begin{array}{l}\text { doi: } \\
\text { 10.1128/AAC } 41.6 .1364\end{array}$ \\
\hline ERS663181 & Afu_1042/09 & India & $\mathrm{C}$ & $\mathrm{R}$ & $\begin{array}{l}\text { doi: } 10.1128 / \mathrm{mBio} .00536- \\
15\end{array}$ \\
\hline ERS663184 & Afu_124/E11 & India & $\bar{E}$ & $\mathrm{R}$ & $\begin{array}{l}\text { doi: } 10.1128 / m B i o .00536- \\
15\end{array}$ \\
\hline ERS663185 & Afu_166/E11 & India & $\mathrm{E}$ & $\mathrm{R}$ & $\begin{array}{l}\text { doi: } 10.1128 / \mathrm{mBio} .00536- \\
15\end{array}$ \\
\hline ERS663187 & Afu_218/E11 & India & $\bar{E}$ & $R$ & $\begin{array}{l}\text { doi: } 10.1128 / \mathrm{mBio} .00536- \\
15\end{array}$ \\
\hline ERS663186 & Afu_257/E11 & India & $\mathrm{E}$ & $\mathrm{R}$ & $\begin{array}{l}\text { doi: } 10.1128 / m B i o .00536- \\
15\end{array}$ \\
\hline ERS663183 & Afu_591/12 & India & $\mathrm{C}$ & $\mathrm{R}$ & $\begin{array}{l}\text { doi: } 10.1128 / m B i o .00536- \\
15\end{array}$ \\
\hline ERS663180 & Afu_942/09 & India & $\mathrm{C}$ & $\mathrm{R}$ & $\begin{array}{l}\text { doi: } 10.1128 / m B i o .00536- \\
15\end{array}$ \\
\hline ERS216929 & AP65 & UK & E & $\mathrm{S}$ & NCBI SRA \\
\hline SRR7418943 & ATCC_204305 & USA & $\mathrm{C}$ & $S$ & doi: $10.3390 /$ genes 9070363 \\
\hline SRR7418935 & ATCC_46645 & UK & $\mathrm{C}$ & $S$ & doi: 10.3390/genes9070363 \\
\hline ERS216946 & CF098 & UK & $\mathrm{C}$ & $S$ & NCBI SRA \\
\hline ERR232405 & CF337 & UK & $\mathrm{C}$ & $\mathrm{R}$ & NCBI SRA \\
\hline SRR7418947 & CM2141 & Spain & $\mathrm{C}$ & $S$ & doi: 10.3390/genes9070363 \\
\hline SRR7418942 & CM237 & Spain & $\mathrm{C}$ & $S$ & doi: 10.3390/genes9070363 \\
\hline SRR7418945 & CM3248 & Spain & $\mathrm{C}$ & $S$ & doi: 10.3390/genes9070363 \\
\hline SRR7418944 & CM5419 & Spain & $\mathrm{C}$ & $S$ & doi: $10.3390 /$ genes 9070363 \\
\hline SRR7418949 & CM5757 & Spain & $\mathrm{C}$ & $S$ & doi: 10.3390/genes9070363 \\
\hline SRR7418936 & CM6458 & Spain & $\mathrm{C}$ & $S$ & doi: $10.3390 /$ genes 9070363 \\
\hline SRR7418938 & CM7555 & Spain & $\mathrm{C}$ & $\mathrm{R}$ & doi: $10.3390 /$ genes 9070363 \\
\hline SRR7418941 & CM7632 & Spain & $\mathrm{C}$ & $S$ & doi: 10.3390/genes9070363 \\
\hline ERR232430 & D17 & UK & $\mathrm{E}$ & $\mathrm{R}$ & NCBI SRA \\
\hline SRR617724 & F12219 & UK & $\mathrm{C}$ & $\mathrm{R}$ & $\begin{array}{l}\text { doi: } \\
10.3201 / \text { eid1507.090043 }\end{array}$ \\
\hline SRR617725 & F12636 & UK & $\mathrm{C}$ & $\mathrm{R}$ & $\begin{array}{l}\text { doi: } \\
10.3201 / \text { eid1507.090043 }\end{array}$ \\
\hline SRR617727 & F13619 & UK & $\mathrm{C}$ & $\mathrm{R}$ & $\begin{array}{l}\text { doi: } \\
10.3201 / \text { eid1507.090043 }\end{array}$ \\
\hline SRR617729 & F14403 & UK & $\mathrm{C}$ & $\mathrm{R}$ & $\begin{array}{l}\text { doi: } \\
10.3201 / \text { eid1507.090043 }\end{array}$ \\
\hline
\end{tabular}


bioRxiv preprint doi: https://doi.org/10.1101/2020.05.24.113787; this version posted May 25, 2020. The copyright holder for this preprint (which was not certified by peer review) is the author/funder. All rights reserved. No reuse allowed without permission.

\begin{tabular}{|c|c|c|c|c|c|}
\hline SRR617731 & F14532 & UK & $\mathrm{C}$ & $\mathrm{R}$ & $\begin{array}{l}\text { doi: } \\
\text { 10.3201/eid1507.090043 }\end{array}$ \\
\hline SRS375803 & F14946G & UK & $\mathrm{C}$ & $S$ & $\begin{array}{l}\text { doi: } \\
\text { 10.3201/eid1507.090043 }\end{array}$ \\
\hline SRR617733 & F15390 & UK & $\mathrm{C}$ & $\mathrm{R}$ & $\begin{array}{l}\text { doi: } \\
\text { 10.3201/eid1507.090043 }\end{array}$ \\
\hline SRR617735 & F16134 & UK & $\mathrm{C}$ & $\mathrm{R}$ & $\begin{array}{l}\text { doi: } \\
\text { 10.3201/eid1507.090043 }\end{array}$ \\
\hline SRS375808 & F16311 & UK & $\mathrm{C}$ & $\mathrm{S}$ & $\begin{array}{l}\text { doi: } \\
\text { 10.3201/eid1507.090043 }\end{array}$ \\
\hline ERR232417 & F17999 & UK & $\mathrm{C}$ & $\mathrm{R}$ & $\begin{array}{l}\text { doi: } \\
10.3201 / \text { eid1507.090043 }\end{array}$ \\
\hline SRS375813 & F18085 & UK & $\mathrm{C}$ & $S$ & $\begin{array}{l}\text { doi: } \\
\text { 10.3201/eid1507.090043 }\end{array}$ \\
\hline ERR232439 & F18304 & UK & $\mathrm{C}$ & $\mathrm{R}$ & $\begin{array}{l}\text { doi: } \\
\text { 10.3201/eid1507.090043 }\end{array}$ \\
\hline ERR232418 & F18329 & UK & $\mathrm{C}$ & $\mathrm{R}$ & $\begin{array}{l}\text { doi: } \\
\text { 10.3201/eid1507.090043 }\end{array}$ \\
\hline ERR232413 & F20140 & UK & $\mathrm{C}$ & $\mathrm{R}$ & $\begin{array}{l}\text { doi: } \\
\text { 10.3201/eid1507.090043 }\end{array}$ \\
\hline ERR232440 & F21572 & UK & $\mathrm{C}$ & $\mathrm{R}$ & $\begin{array}{l}\text { doi: } \\
\text { 10.3201/eid1507.090043 }\end{array}$ \\
\hline ERR232414 & F21732 & UK & C & $\mathrm{R}$ & $\begin{array}{l}\text { doi: } \\
\text { 10.3201/eid1507.090043 }\end{array}$ \\
\hline ERR232421 & F21857 & UK & $\mathrm{C}$ & $\mathrm{R}$ & $\begin{array}{l}\text { doi: } \\
\text { 10.3201/eid1507.090043 }\end{array}$ \\
\hline ERS216942 & F4S1B & UK & $\mathrm{E}$ & $\mathrm{S}$ & NCBI SRA \\
\hline SRS375812 & F5211G & UK & $\mathrm{C}$ & $S$ & $\begin{array}{l}\text { doi: } \\
\text { 10.3201/eid1507.090043 }\end{array}$ \\
\hline SRS375815 & F7763 & UK & $\mathrm{C}$ & $S$ & $\begin{array}{l}\text { doi: } \\
\text { 10.3201/eid1507.090043 }\end{array}$ \\
\hline SRR4002443 & ISSFT-021 & $\begin{array}{l}\text { International } \\
\text { Space Station }\end{array}$ & $\mathrm{E}$ & $\mathrm{S}$ & $\begin{array}{l}\text { doi: } \\
10.1128 / \mathrm{mSphere} .00227-16\end{array}$ \\
\hline ERR232441 & RSF2S8 & UK & $\mathrm{E}$ & $\mathrm{R}$ & NCBI SRA \\
\hline ERS216922 & SF1S5 & UK & $\mathrm{E}$ & $\mathrm{S}$ & NCBI SRA \\
\hline ERS216948 & SF1S6 & UK & $\mathrm{E}$ & $\mathrm{S}$ & NCBI SRA \\
\hline ERS216938 & SF2S6 & UK & $\mathrm{E}$ & $S$ & NCBI SRA \\
\hline ERS216937 & SF3S1 & UK & $\mathrm{E}$ & $\mathrm{S}$ & NCBI SRA \\
\hline ERS216930 & SF3S10 & UK & $\mathrm{E}$ & $\mathrm{S}$ & NCBI SRA \\
\hline ERS216918 & SF4S10 & UK & $\mathrm{E}$ & $S$ & NCBI SRA \\
\hline ERR769507 & $08-36-03-25$ & Netherlands & $C$ & $R$ & $\begin{array}{l}\text { doi: } 10.1128 / m \text { Bio.00536- } \\
15\end{array}$ \\
\hline ERS663182 & $A f u \_343 / P / 11$ & India & $C$ & $R$ & $\begin{array}{l}\text { doi: } 10.1128 / m \text { Bio.00536- } \\
15\end{array}$ \\
\hline SRR7841978 & DI_15-102 & USA & $C$ & $R$ & $\begin{array}{l}\text { doi: } 10.1128 / \mathrm{mBio} .00437- \\
20\end{array}$ \\
\hline SRR7841983 & DI_15-106 & USA & $C$ & $R$ & $\begin{array}{l}\text { doi: } 10.1128 / \mathrm{mBio} .00437- \\
23\end{array}$ \\
\hline SRR7841993 & DI_15-96 & USA & $C$ & $R$ & $\begin{array}{l}\text { doi: } 10.1128 / \text { mBio.00437- } \\
36\end{array}$ \\
\hline SRR7842000 & DI_15-116 & USA & $C$ & $R$ & $\begin{array}{l}\text { doi: } 10.1128 / m \text { Bio.00437- } \\
31\end{array}$ \\
\hline
\end{tabular}


bioRxiv preprint doi: https://doi.org/10.1101/2020.05.24.113787; this version posted May 25, 2020. The copyright holder for this preprint (which was not certified by peer review) is the author/funder. All rights reserved. No reuse allowed without permission.

SUPPLEMENTARY TABLE S4. Fungicide resistance genotypes and growth phenotypes for agricultural isolates from Georgia and Florida.

\begin{tabular}{lcccccc} 
Isolate & $\begin{array}{c}\text { cyp51A } \\
\text { genotype }\end{array}$ & $\begin{array}{c}\text { Growth on } \\
\text { Azole }\end{array}$ & $\begin{array}{c}\text { cytB } \\
\text { genotype }\end{array}$ & $\begin{array}{c}\text { Growth on } \\
\text { QoI }\end{array}$ & $\begin{array}{c}\text { benA } \\
\text { genotype }\end{array}$ & $\begin{array}{c}\text { Growth on } \\
\text { MBC }^{\mathbf{c}}\end{array}$ \\
\hline eAF77 & WT & - & WT & - & WT & - \\
\hline eAF94 & WT & - & WT & - & WT & - \\
\hline eAF537 & WT & - & WT & - & WT & - \\
\hline eAF222 & $\mathrm{TR}_{46} / \mathrm{Y} 121 \mathrm{~F} / \mathrm{T} 289 \mathrm{~A}$ & + & $\mathrm{G} 143 \mathrm{~A}$ & + & $\mathrm{WT}$ & - \\
\hline eAF233 & $\mathrm{TR}_{46} / \mathrm{Y} 121 \mathrm{~F} / \mathrm{T} 289 \mathrm{~A}$ & + & $\mathrm{G} 143 \mathrm{~A}$ & + & $\mathrm{F} 219 \mathrm{Y}$ & + \\
\hline eAF234 & $\mathrm{TR}_{46} / \mathrm{Y} 121 \mathrm{~F} / \mathrm{T} 289 \mathrm{~A}$ & + & $\mathrm{G} 143 \mathrm{~A}$ & + & $\mathrm{F} 219 \mathrm{Y}$ & + \\
\hline eAF513 & $\mathrm{TR}_{46} / \mathrm{Y} 121 \mathrm{~F} / \mathrm{T} 289 \mathrm{~A}$ & + & $\mathrm{G} 143 \mathrm{~A}$ & + & + \\
\hline
\end{tabular}

${ }^{a}$ One hundred conidia were inoculated to solid medium containing $3 \mu \mathrm{g} / \mathrm{ml}$ tebuconazole (TEB) and incubated at $37^{\circ} \mathrm{C}$ for $23-24 \mathrm{~h}$. These isolates also had MICs $\geq 16 \mu \mathrm{g} / \mathrm{ml}$ in TEB liquid medium (Table 1 ).

${ }^{\mathrm{b}}$ One hundred conidia were inoculated to solid medium containing $10 \mu \mathrm{g} / \mathrm{ml}$ azoxystobin and incubated at $37^{\circ} \mathrm{C}$ for 23-24 h.

${ }^{\mathrm{c}}$ One hundred conidia were inoculated to solid medium containing $10 \mu \mathrm{g} / \mathrm{ml}$ benomyl and incubated at $37^{\circ} \mathrm{C}$ for $23-$ 

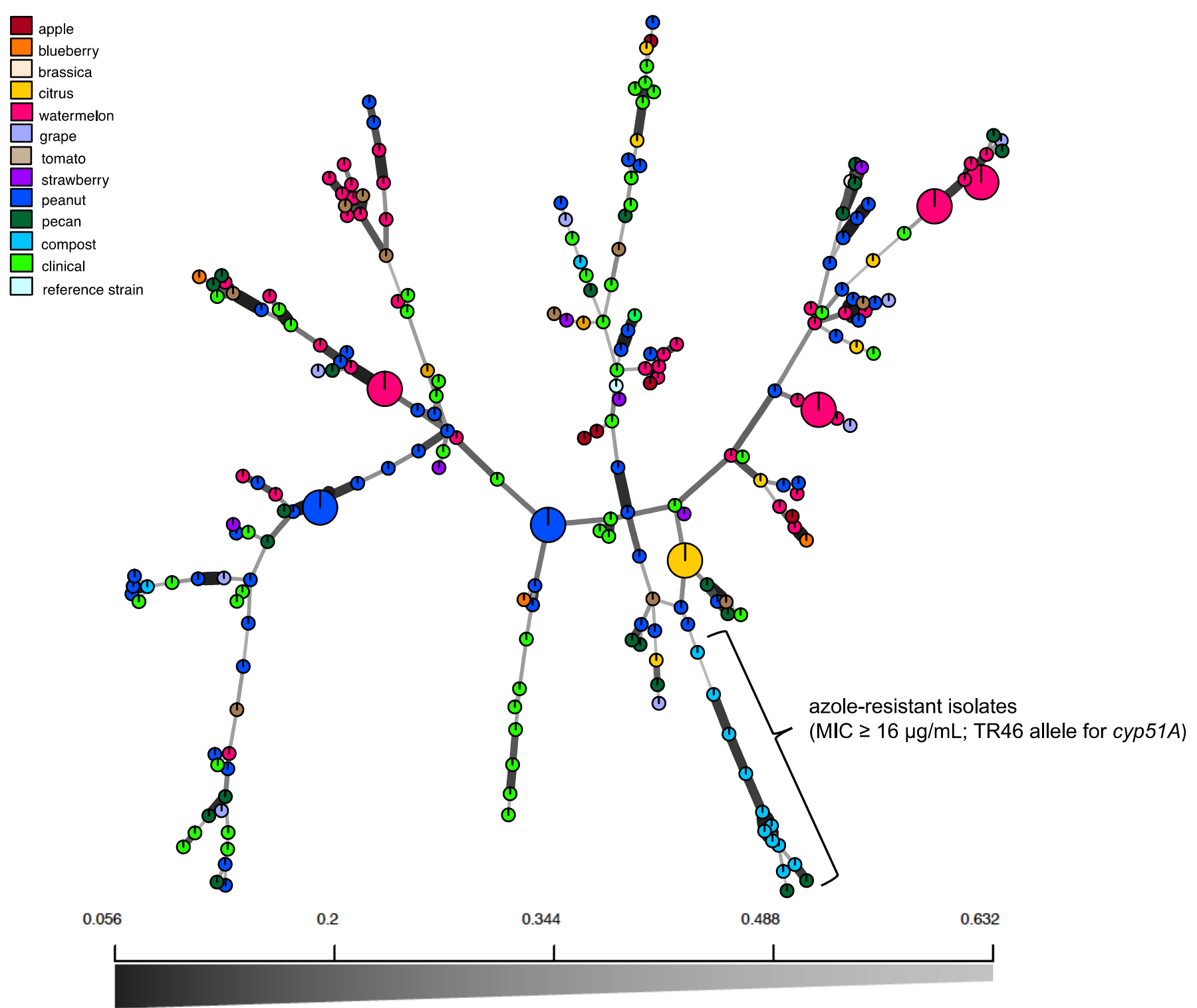

Supplementary Figure S1. Minimum spanning network based on Bruvo's genetic distance of agricultural and clinical isolates of A. fumigatus from Georgia and Florida. Isolates (168 agricultural and 48 clinical) were genotyped with 9 STR $A f$ markers. Each circle represents a unique haplotype and the size of the circle represents the relative frequency of detection. The color of each circle represents the environment where the isolate was collected. Thicker lines represent shorter genetic distances. Individuals with the TR46/Y121F/T289A allele for cyp51A are shown in the lower right. 


\section{Supplementary Figure S2}
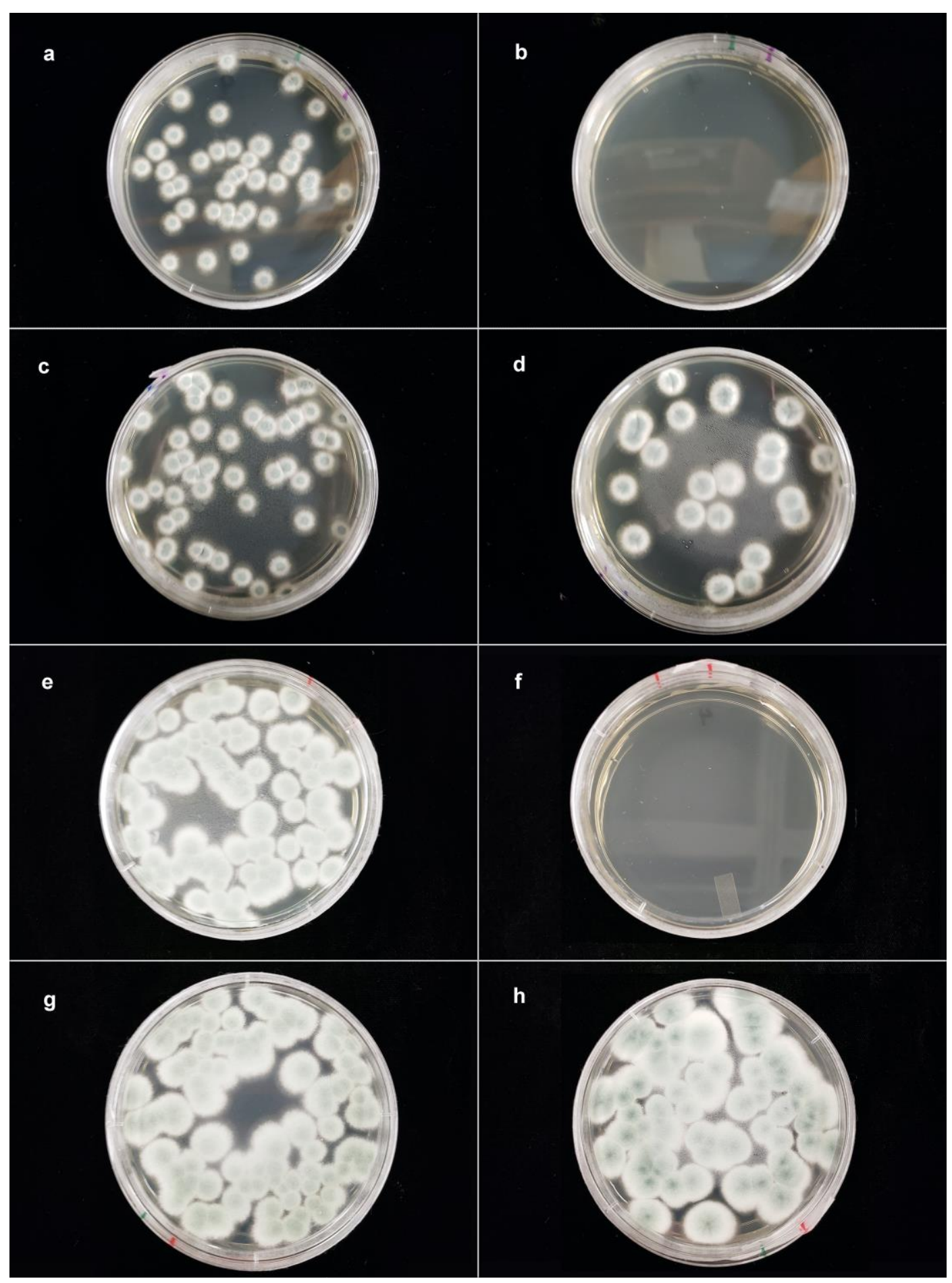

Supplementary Figure S2. Pan-azole-resistant A. fumigatus (cyp51A $\mathrm{TR}_{46} / \mathrm{Y} 121 \mathrm{~F} / \mathrm{T} 289 \mathrm{~A}$ ) with cytB G143A and benA F219Y mutations are resistant to quinone outside inhibitor (QoI) and benzimidazole (MBC) fungicides. Left column (a, c, e, g) multi-fungicide-resistant isolate eAF222. Right column (b, d, f, h) sensitive isolate eAF94. (a, b) SDA (Sabouraud dextrose agar) + the QoI fungicide azoxystrobin + salicylhydroxamic acid (SHAM). (c, d) SDA medium + SHAM. (e,f) SDA medium + the MBC fungicide benomyl. $(\mathrm{g}, \mathrm{h})$ SDA medium. 